
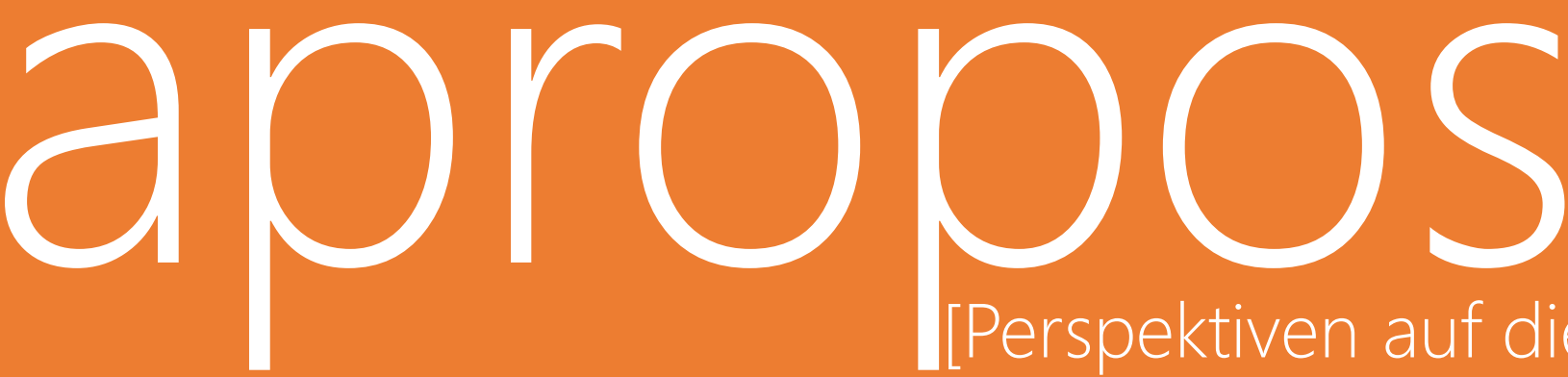

\title{
[Perspektiven auf die Romania]
}

Sprache/Literatur/Kultur/Geschichte/Ideen/Politik/Gesellschaft

"Yo soy Vegeta y cuando jugué con Messi me hice Súper Saiyajin»

Biografización y socialización otaku, entre la nostalgia y el sincretismo cultural

Federico Álvarez Gandolfi \& Gerardo Ariel Del Vigo

apropos [Perspektiven auf die Romania]

hosted by Hamburg University Press

2021, 7

pp. $60-77$

ISSN: 2627-3446

Online

https://journals.sub.uni-hamburg.de/apropos/article/view/1834

\section{Zitierweise}

Álvarez Gandolfi, Federico \& Gerardo Ariel Del Vigo. 2021. „"Yo soy Vegeta y cuando jugué con Messi me hice Súper Saiyajin». Biografización y socialización otaku, entre la nostalgia y el sincretismo cultural." apropos [Perspektiven auf die Romania] 7/2021, 60-77. doi: https://doi.org/10.15460/apropos.7.1834 


\title{
Federico Álvarez Gandolfi \& Gerardo Ariel Del Vigo
}

\section{"Yo soy Vegeta y cuando jugué con Messi me hice Súper Saiyajin»}

\author{
Biografización y socialización otaku, entre la nostalgia y el sincretismo \\ cultural
}

\author{
Federico Álvarez Gandolfi \\ es Doctor en Ciencias Sociales por la \\ Universidad de Buenos Aires y becario \\ de CONICET \\ federicoalvarezg@gmail.com \\ Gerardo Ariel Del Vigo \\ es maestrando en Comunicación y \\ Cultura en la Facultad de la \\ Universidad de Buenos Aires \\ gadelvigo@yahoo.com.ar
}

Palabras clave
otakismo - waifuismo - identidades - nostalgia - sincretismo

\section{Consideraciones iniciales}

Durante la última década comenzó a establecerse con fuerza cierta postura desde la cual se sugiere que estamos asistiendo a un proceso de normalización del fanatismo entre las audiencias (Coppa 2014), en un panorama de mercantilización social y digitalización. Así suele afirmarse que los estereotipos negativos sobre los fans en general y los otakus en particular, identificados en un trabajo anterior (ver Borda \& Álvarez Gandolfi 2014), se han desplazado y ya no operarían en sus representaciones sociomediáticas estigmatizadoras. Tal desplazamiento respondería a que sus consumos culturales hoy serían celebrados y legitimados globalmente dada una supuesta valoración positiva que habrían cobrado tanto la diversidad cultural como las imágenes del geek (Geraghty 2014).

Ocurre que considerar a priori que el fanatismo se ha normalizado y legitimado conlleva el riesgo de pensar las identidades que pueden construirse a partir de este como si hubiera una relación de necesidad entre visibilización y aceptación generalizada (ver Álvarez Gandolfi 2017). Así termina por presentarse la idea de que el fandom constituye una comunidad homogénea basada en gustos, prácticas y valores compartidos, foco que tiende a atravesar el campo de estudios sobre 
otakus en América Latina (García Núñez \& García Huerta 2014) aún en vías de constitución.

Por lo tanto, las reflexiones que desarrollaremos en estas páginas giran en torno de la heterogeneidad, las dinámicas y las tensiones, las contradicciones y las asimetrías que sobrevuelan las identidades que pueden construirse sobre la base del consumo fan de objetos transculturales como el animé. Pese a que en un principio pareciera primar en este fandom una lógica de unificación, resulta fundamental reconstruir sus complejidades y fragmentaciones mediante un análisis de los diferentes significados y valores de sus prácticas y experiencias (Álvarez Gandolfi 2017).

Aquí nos centraremos en los cruces entre lo nacional y lo transnacional que caracterizan los prosumos otaku y la socialización sexoafectiva de estos fans en un marco de sincretismo o hibridación cultural (Del Vigo 2018). La argentinidad y la japonesidad son mitos que se hacen presentes en el consumo de animé y las identidades fan que se derivan de este. Asimismo, revisaremos los cruces entre lo alternativo y lo mainstream que habilitan una complejización de la presupuesta «normalización» de este fanatismo, extrapolando la hipótesis central alrededor del fanatismo como un fondo de recursos diversos (Borda 2012) en pos de considerar la nostalgia como un recurso disponible tanto para las industrias culturales como para la construcción de identidades fan personales y colectivas, según puede ilustrarse a partir del otakismo (Álvarez Gandolfi 2014; 2016).

Lo local, lo global, lo resistente y lo dominante son pilares en las significaciones identitarias producidas por los otakus. Y es por ello que deben ser sometidos tanto a una sistematización y reconstrucción de sus racionalidades integradoras como a una problematización de sus dinámicas expulsivas. Para ello, partiremos de una explicitación de términos e inquietudes que orientan nuestras aproximaciones a este fenómeno, conceptos y preocupaciones ligadas a los estudios culturales y a los estudios sobre fans que iremos poniendo a prueba en el análisis de algunos casos representativos del fandom, relevados en nuestros respectivos trabajos de campo.

\section{El consumo como campo de batalla por el sentido}

Una pregunta inicial que nos hacemos consiste en cómo pensar los consumos mediático-culturales y las identidades que pueden construirse a partir del fanatismo por las animaciones japonesas en la Argentina. Para empezar, podría considerarse que estos consumos y sus implicaciones en las construcciones identitarias vinculadas con el otakismo pueden interpretarse dentro de un contexto cuya lógica cultural se corresponde con el posmodernismo, panorama en el que nuestras experiencias se ven atravesadas por apropiaciones de diferentes bienes provistos por un mercado cultural globalizado.

Lo que pareciera ser común a estos sujetos en particular y a los fans en general es la construcción de identidades fuertemente definidas por consumos mediáticoculturales, en busca de nuevos referentes y estabilidades frente a la pérdida de reconocimientos y credibilidades en las instituciones tradicionales modernas. En las sociedades contemporáneas seculares, habitamos un mundo impredecible dado que hemos perdido todo sustrato único, ante la crisis de los grandes relatos 
(Lyotard 1987). Esto permite la convivencia de múltiples referencias locales y globales alrededor de las cuales estructurar la experiencia. Jesús Martín-Barbero (1995) refiere a un cruce entre dos concepciones de secularización latinoamericana: la historicista, que implica la identificación de la historia de los pueblos con la historia de los Estados; y la populista, que implica la identificación de las masas populares con la reserva moral de los países. Estas tensiones pueden ilustrarse, por ejemplo, con el caso del culto al Gauchito Gil asociado con la religiosidad popular argentina y su apropiación por parte de los otakus en forma de figura de acción que remite al título japonés Dragon Ball $Z^{1}$.

El hecho de pensar el consumo de objetos transculturales como una suerte de pastiche se vincula con la consideración de la estética del videoclip (Landi 1992), lógica visual-cultural de las sociedades posmodernas que confluye en el simulacro, obra original sobre la base de una copia ya sin referente. En este sentido, el «Gauchito Gil Z» solo interpela en su complejidad a quienes estén atravesados por los relatos de la religiosidad popular argentina y, al mismo tiempo, por los relatos de la cultura de masas japonesa.

No obstante, si bien se entiende que la lógica del videoclip impera en la posmodernidad, son igual de ciertas las advertencias de Beatriz Sarlo (1994): en dicha estética también se cimientan «viejos relatos», de modo que el potencial emancipatorio de las prácticas de consumo vinculadas con el otakismo puede debatirse. De hecho, la ya mencionada figura de acción paródica no hace más que reconfirmar el estatus de cita como recurso fundamental de la comicidad de hoy. Así pueden comprenderse las relaciones de los fans con la cultura pop como consumista y celebratoria, a la vez que como crítica y hedonista.

En esto consiste la aparente contradicción posmoderna, ilustrada en el modo en que una apropiación secular de la cultura de masas puede poner en juego diversos frentes culturales para afirmar las identidades otaku desde el consumo, resistiendo al persistente prejuicio de la sociedad en general y de los medios de comunicación en particular. Aun así, estos fans desplieguen lógicas de socialización poco transformadoras de la realidad: por ejemplo, en la mayoría de los grupos de Facebook donde interactúan, se exige no hablar de temas ajenos a los objetos japoneses o a las prácticas que implican más allá de la visualización del animé, como la asistencia a convenciones o encuentros entre pares en los que lo más importante es la compra de merchandising, el espectáculo musical de quienes interpretan canciones de las animaciones niponas y el concurso de cosplay, es decir, la caracterización de personajes ficcionales mediante vestimentas, accesorios y actuaciones respectivas (Álvarez Gandolfi 2014; Del Vigo y Carpenzano 2014).

Beatriz Sarlo habla de una sociedad en la que los medios difunden a los héroes de subculturas, ahora cada vez más signada por lazos débiles o líquidos. Si la televisión proponía una cultura de espejo, internet propone una de prismas, multiplicando

${ }^{1}$ El sincretismo entre el Gauchito Gil, santo popular argentino, y Son Goku, protagonista de Dragon Ball Z (Toriyama, 1989), es una marca de la popularización que atraviesa la identidad otaku, entre un cuatrero que repartía su botín entre los pobres y un héroe venerado por dichos fans de modo irónico, respectivamente. 
imágenes en incontables facetas y variaciones. Este espacio cuasi esquizofrénico permite la gestación de identidades simultáneas, espontáneas, mercantilizables y fugaces (Del Vigo 2018).

Ahora bien, frente a esta liquidez y fugacidad posmodernas, podríamos recuperar la pregunta del ya citado Jesús Martín-Barbero (1995): ¿qué convoca hoy a la gente a juntarse? ¿Cuáles son las modalidades del estar juntos? Frente al desencanto producido por la caída de los grandes relatos de la modernidad, los sujetos quedan a merced de la experiencia oceánica (Berardi 2017), tratando de aferrarse a un mito o a un rito (Del Vigo 2018). A pesar de las promesas de liberación, la apertura de los límites profundizó la angustia identitaria dado que los sujetos siguen necesitando producir sentidos de pertenencia, para lo cual el otakismo aparece como recurso fundamental (Álvarez Gandolfi 2014).

Si bien Beatriz Sarlo afirma que «dónde estaba la política aparecieron los movimientos sociales, y hoy avanzan las neo-religiones» $(1994,41)$, caben algunos reparos en la posibilidad de catalogar al fanatismo por los bienes culturales nipones como una «neo-religión», fundamentalmente dado el manto de «irracionalidad» que recubre al término. Creemos más conveniente la comprensión de las prácticas de los otakus en el marco de un reencantamiento del mundo a través de los medios. $\mathrm{O}$, como sostiene Martín-Barbero:

Los medios de comunicación no son un puro fenómeno comercial, no son un puro fenómeno de manipulación ideológica, son un fenómeno antropológico, son un fenómeno cultural a través del cual la gente, mucha gente, cada vez más gente, vive la constitución del sentido de su vida $(1995,4)$.

Los fans de objetos de la cultura de masas japonesa no solo producen significaciones a partir de sus relaciones familiares y sociales inmediatas, sino también de sus vínculos con los contenidos mediáticos que consumen y de sus encuentros presenciales con pares en juntadas, eventos o convenciones de animé, formando comunidades de práctica tanto presencialmente como a través de las redes sociales, con normas protocolares implícitas o explícitas que rigen los intercambios.

Ante el aparente vaciamiento de las estructuras modernas, los fans resignifican su experiencia social a través de plataformas como Facebook, Twitter, DeviantArt, Fanfiction.net, Wattpad y foros, así como también participan en eventos especializados dentro de un circuito comercial de nicho. Este efecto de la magia tecnológica, esa performatividad farmacopornográfica ${ }^{2}$ de la subjetividad (Preciado 2008), hace capaz de volver trascendente lo aparentemente inocuo desde una óptica de "la alta cultura». Los dispositivos son los lugares de visibilización de ciertos mitos comunes que unen, protegen, dan sentido a la pobre vida de la mayoría (Martín-Barbero 1995). Y los otakus no solo se apropian de los productos de las industrias culturales japonesas como factor aglutinante de

\footnotetext{
${ }^{2}$ La performatividad farmacopornográfica se refiere a la forma capitalista de subjetivación a través del consumo de mercancías para saciar la frustración, según el modelo de la industria pornográfica que genera una adicción sostenida a través de la dependencia a la industria farmacéutica.
} 
socialización entre pares, sino también para realizar prácticas de prosumo o producción a partir del consumo y así forjar nuevos bienes culturales, simulacros insignificantes para los agentes externos, pero fundamentales para estos sujetos.

Es en este sentido que insistimos en la importancia de entender al consumo como uso, apropiación, tácticas (de Certeau 1996) que implican el despliegue de prácticas de bricolaje. Esta concepción permite analizar las dinámicas de las relaciones entre fans e industrias culturales en toda su complejidad, cada vez más globalizadas y digitalizadas. Extrapolando de modo actualizado las observaciones de Guillermo Sunkel (2002), advertimos las tensiones entre la industria transnacional del entretenimiento que pareciera ganar peso frente a las tradiciones locales y el hogar a través del cual es posible la conexión con una cultura deslocalizada, sin que ello implique abandonar las significaciones nacionales, sino más bien ponerlas en diálogo con nuevos referentes. Por eso los otakus se han convertido en la subcultura online más grande del mundo (Ito 2012), según puede observarse también en el hecho de que prácticas relacionadas con Japón han traspasado fronteras, como el cosplay y el waifuismo (Del Vigo y Carpenzano 2014; Del Vigo 2018). Todas dimensiones del otakismo que, en primera instancia, provienen del consumo de objetos de la cultura de masas japonesa (Álvarez Gandolfi 2014; 2016).

Tales prácticas, núcleos de los devenires de la socialización otaku, se anclan en la cultura del simulacro. El waifuismo, particularmente, pone en juego construcciones identitarias a partir de la vinculación sexoafectiva con un personaje de animé, manga o videojuegos, que abarca desde una mención paródica hasta un sentimiento de comunión con el objeto de afecto (Del Vigo 2018). Al considerar al fan como prosumidor, también se concibe a la relación waifu como una manifestación del fanatismo que excede al contenido original, en este caso, al personaje elegido como waifu (transliteración japonesa del inglés wife, esposa) o husbando (del inglés husband, esposo). Los waifuistas idolatran a su cónyuge de ficción mediante el consumo de todo su merchandising: pósters, peluches, figuras de colección, tazas, remeras, CD Dramas ${ }^{3}$, OVA $^{4}$, pins o prendedores $y$, principalmente, las dakimakura, fundas de almohada con la imagen del personaje amado. Cuando este consumo no es suficiente, se comprometen con otras prácticas fan: fanfiction ${ }^{5}$, shipping ${ }^{6}$, cosplay $^{7}$, fanart $^{8}$.

Pero, según ya advertimos, la socialización y los prosumos implicados en el otakismo conllevan cruces entre narrativas nacionales y transnacionales, los cuales suelen ser teorizados en términos de sincretismo o hibridación cultural (García Canclini 1995). Y ello no solo puede ilustrarse a partir del cosplay y del waifuismo, sino también a partir de la producción y la circulación de memes. Así, los otakus argentinos se apropian de bienes originados en la cultura japonesa y les impregnan

\footnotetext{
${ }^{3} \mathrm{CD}$ con diálogos de animé, al estilo del radioteatro.

${ }^{4}$ Original Video Animation, es decir, especiales de animé publicados directamente en video.

${ }^{5}$ Escritura fan de fics, relatos de ficción basados en un texto fuente que puede continuarlo o reescribirlo.

${ }^{6}$ Práctica que consiste en proponer emparejamientos entre personajes no vinculados en las obras originales.

${ }^{7}$ Contracción del término costume play («juego de disfraces»), que implica la confección amateur de trajes de personajes de manga, animé, videojuegos, series y películas.

8 llustraciones basadas en reinterpretaciones de productos culturales que suelen monetizarse.
} 
rasgos locales e incluso nuevos sentidos de pertenencia. Referencias internas que, de modo cíclico, se comercializan en forma de merchandising tanto en convenciones como en plataformas digitales.

Entonces, los otakus pueden ser tomados como un caso paradigmático que ilustra la importancia que ha cobrado el consumismo como una instancia fundamental de la experiencia social, ya que mediante las prácticas de consumo se construye parte de la racionalidad integrativa y comunicativa de las sociedades. Sociedades que sientan sus bases en una racionalidad posmoderna dado que sus miembros, a pesar del agotamiento de los grandes relatos, buscan estructuras sobre las cuales organizar sus vidas, buscan rituales, fijar significados. El fandom del animé en general no escapa de este orden: desde las reglas que rigen los intercambios en un grupo de Facebook o en un foro hasta las normas tácitas y móviles que indican que un cosplay es válido si el cosplayer da con la apariencia del personaje interpretado, todas formas de regulación.

Como afirman Mary Douglas y Baron Isherwood (cfr. 1979), al consumir, se liga la insatisfacción con el flujo errático de los significados. Por lo tanto, consumir, ser otaku, deviene en poder pensar el mundo y hacerlo inteligible, reencantarlo. Según sostiene Néstor García Canclini (1995), el consumo es uno de los procesos por los cuales los deseos se convierten en demandas y en actos socialmente regulados que conforman comunidades transnacionales de consumidores. Así, puede pensarse que los otakus construyen comunidades de pertenencia y control que están en permanente reestructuración. En este tiempo de fracturas y heterogeneidad, el consumo de objetos de la cultura de masas japonesa establece códigos que los unifican globalmente entre pares.

De todos modos, códigos como los de la nación o la etnia persisten gracias su adaptación en pactos móviles de lectura de los bienes y los mensajes transnacionales, sobre cuya base se generan mezclas sincréticas o híbridas tanto a nivel del contenido o de la producción como a nivel de la recepción o del prosumo. En el primer caso, tales mezclas permiten que, para un otaku argentino, la patria sea representada por personajes como Juan Díaz, el capitán de la Selección Argentina en Captain Tsubasa de Takahashi, basado en Diego Armando Maradona; Albiore de Cefeo, uno de los caballeros en Saint Seiya de Kurumada, presente en un banner de la Fan Page de Facebook de Animé Doblaje Argentino, combinado con emblemas considerados como representativos de lo nacional como la gaseosa Manaos, las galletitas Pitusas, el mate, el choripán y los dos dedos de la $\mathrm{V}$ de la victoria, signo asociado tanto al triunfo y a la paz como al peronismo; o Tooru Oikawa, jugador de vóleibol en Haikyuu!! de Furudate que se nacionaliza argentino al final del manga y protagoniza un meme en el que se lo muestra rodeado por dos premios Óscar, dos copas del mundo de la FIFA y cinco premios Nobel.

En el segundo caso, el del nivel del prosumo, las mezclas sincréticas o híbridas entre los códigos de la nación y los mensajes transnacionales habilitan la producción de memes paródicos en los que se resignifican referentes de títulos japoneses como Mikami, la cazafantasmas mediante su contraste con la letra de "La colorada», una 
canción de cumbia villera (género musical usualmente considerado como representativo de «lo argentino») compuesta por Pibes Chorros.

Entonces, podemos pensar que los otakus forman parte de una comunidad interpretativa de consumidores, que se relacionan de un modo particular con los objetos transculturales en las plataformas digitales, reapropiándoselos y resignificándolos. Así, tanto las animaciones japonesas como sus fans vendrían a ser parte de lo que Renato Ortiz (1997) denominaría cultura internacional-popular. Ante el debilitamiento de lo nacional, las identidades se construyen a través de la participación en el consumo global.

\section{Otro rodeo por los prosumos otaku como síntoma del sincretismo cultural}

Según ya se indicó, las ideas de De Certeau y García Canclini permiten comprender el consumo como un conjunto de prácticas y procesos socioculturales por los cuales se realizan los usos y las apropiaciones de los productos, se producen desvíos y resignificaciones fundamentales en las construcciones identitarias de la época contemporánea. Los actos de consumo implican mucho más que una acción irreflexiva o que el ejercicio de un gusto que, en términos bourdieuanos, vendría a reproducir el orden social: dan lugar a una reflexión sobre la dimensión artística de las sociedades posmodernas en las que muchos conciben que todavía vivimos.

La estetización de las experiencias sociales se conjuga con la secularización referida anteriormente, como otro modo de significar, socializar y buscar nuevos referentes para estructurar las identidades. Todas estas dimensiones convergen sincréticamente en la cultura del simulacro, instituyendo frentes culturales cada vez más globalizados que se entremezclan con las experiencias individuales cada vez más localizadas.

Las prácticas de prosumo otaku son un ejemplo de esto, en la medida en que podrían ser leídas a la luz de una customización de la experiencia. A partir del consumo de las narrativas transnacionales que circulan por los bienes culturales japoneses, estos fans no solo producen discursos para entender sus propias vivencias nacionales, sino que también se involucran en un proceso de socialización entre pares tanto offline como online y crean sus propios textos. Dicha productividad es la que da lugar a la configuración de su fandom a partir de la mixtura de diversos elementos, en un contexto signado por un aumento de los desplazamientos mediáticos y digitales de prácticas artísticas, políticas y de «alta cultura» en el marco de una cultura participativa propia de los fans (Jenkins et al. 2016).

Internet como medio, las redes sociales y la arquitectura de las plataformas digitales como dispositivos de mediación cultural son el factor principal de proliferación de comunidades de guardarropa (Bauman 2003), concepto que puede aplicarse a los otakus y a los cosplayers (Del Vigo y Carpenzano 2014). Mediante los mencionados procesos de construcción identitaria y de configuración comunitaria, el consumo cultural se constituye como herramienta de identificación para estos fans, entre una multiplicidad de opciones simbólicas que constituyen la oferta de 
interpelación dentro del contexto posmoderno. Y es por ello que pueden consumir tanto animé como objetos culturales más visibles y legítimos: mate, choripanes, cumbia, rock nacional, películas y series no necesariamente japonesas o adaptaciones argentinas como Casados con hijos.

En los fandoms el valor de uso tiende a cobrar más importancia que el valor de cambio (Hills 2002) ya que no solo permite crear nuevas mercancías, sino fundamentalmente constituir códigos intracomunitarios que refuerzan rituales y mitos de unificación que dan cohesión a las culturas fan. Es así que las mercancías otaku proporcionan medios de subsistencia cultural y comunitaria: para estos fans, consumir es análogo a producir y a pertenecer. De esta manera, su prosumo permite no solo observar la reproducción de fuerzas, sino también la producción de sentidos entendida como una lucha cultural, posicional, por un capital simbólico.

Como sucede con la mercantilización del arte, los productos preferidos por estos fans solo revisten un interés para quien está provisto de esa cultura, del código que rige la significación dentro de sus límites porosos. En los stands de los eventos de animé, se vende todo tipo de merchandising, no solo ofertado por la industria, sino en su mayoría mercancías fan, es decir, productos no oficiales que interpelan directamente a los otakus, mezclando identidades fan con identidades nacionales. Dentro de estos eventos es usual ver ofertas de mercancías fan que apelan a una interpretación del peronismo como sinónimo de barato y popular, como por ejemplo mediante referencias a una «caja peronista» de precio accesible para «el pueblo otaku».

El arte, la política, la nación, la religión y otros grandes relatos se funden con la cultura de masas dando lugar a transgresiones, como ocurre en los casos ya mencionados del «Gauchito Gil Z», de la apropiación de personajes japoneses para generar identificaciones nacionalistas y de la producción de memes en los que se ponen a dialogar referentes locales y transnacionales. Transgresiones que son posibles en la medida en que las interacciones contemporáneas ya no cuentan con un gran relato que las organice, sino que se producen en la intersección de múltiples significaciones, dando lugar a un simulacro.

Por lo tanto, podemos pensar al fandom otaku como una comunidad que surge y se desarrolla gracias a la productividad ejercida en una cultura de consumo, con fundamentos híbridos que negocian la legitimidad de su pertinencia limitados por la producción de sentido atravesada por imaginarios y discursos hegemónicos desde los que se sigue estereotipando a estos fans, puestos en escena como amenazas a la cordura social, «anormales» o «inmaduros». Imaginarios y discursos que no solo se hacen presentes en las prefiguraciones de agentes externos, sino que también son reproducidos por los propios otakus, pues se sigue concibiendo a estos objetos, sujetos y prácticas culturales como motores de actividades y relaciones ilegítimas. En efecto, dentro del fandom otaku se reproducen las jerarquías y las asimetrías que rigen el espacio social (Álvarez Gandolfi 2014; 2017), lo que se ilustra por ejemplo en las disputas entre los sentidos y valores en torno del cosplay basado en productos culturales japoneses (Del Vigo y Carpenzano, 
2014). La expansión de las prácticas de consumo de objetos de la cultura de masas japonesa se ve atravesada por una acentuación de los conflictos entre pares.

\section{La nostalgia, ¿factor aglutinante o expulsivo?}

Según lo hemos analizado hasta este punto, pareciera que la hibridación cultural es uno de los procesos centrales que dan lugar al surgimiento de identidades y comunidades vinculadas con el otakismo. Es en el marco de este fenómeno, estrechamente relacionado con la globalización y cada vez más estimulado por la digitalización, que se amplía el acceso al consumo de objetos de la cultura de masas japonesa en Occidente en general y en la Argentina en particular. Lo observado en los anteriores subtítulos nos permite comprender las mezclas entre simbolismos diversos y las dinámicas de integración que hacen a este fandom. En efecto, por estos lares se reconfirman en parte las lógicas advertidas en otros trabajos que explican cómo se configuran los núcleos identitarios y comunitarios centrales de los otakus, alrededor del cosmopolitismo y de la alternatividad (Jenkins et al. 2016; Eng 2012). Es posible pensar que, sobre la base de estas significaciones comunes, las cuales según se explicará remiten a narrativas de la nostalgia (Gerarghty 2014; 2018), estos fans procesan discursivamente el impacto biográfico que tienen sus consumos de productos como el animé, asignándole relevancia tanto a lo local como a lo global, tanto a lo personal como a lo colectivo.

Como señalamos, en las sociedades contemporáneas asistimos a un estallido de los grandes relatos cuyo correlato pareciera ser la pluralización de referentes identitarios propuestos por el mercado global (Martín-Barbero 2008). Esta es una de las ideas que están detrás de los planteos jenkinsianos sobre las lógicas del «cosmopolitismo pop» que sería característico de la época actual: la posibilidad de construir una «identidad alternativa» a partir del consumo de bienes simbólicos extranjeros que «resisten» las tendencias homogeneizadoras de las propias naciones.

Desde una postura contraria a la del entendimiento del mundo globalizado como producto de una estandarización cultural, llega a afirmarse que, a través de los flujos transculturales, se puede salir del aislamiento de las propias sociedades. Y ello debido a la erosión de fronteras y al acceso a una multiplicidad de referentes simbólicos cuya combinación da lugar a la configuración de culturas híbridas (García Canclini 1995). Así, paradójicamente, podrían conformarse identidades y comunidades cosmopolitas diferenciadas sobre la base de consumos de objetos transnacionales de la cultura pop. De aquí que los otakus formarían parte de un fandom alternativo a las corrientes dominantes de producción, circulación y consumo, signado por cierta condición «esotérica» y «resistente» dada la posesión de conocimientos intracomunitarios (Ito 2012).

Ahora bien, en las últimas décadas, las industrias culturales japonesas empezaron a verse cada vez más como fuente de poder capaz de competir y desplazar la hegemonía del entretenimiento estadounidense, capacidad en la que radica su atractivo para una parte considerable de sus consumidores según pudo relevarse en los propios trabajos de campo que tomamos en cuenta en este artículo. 
Entonces, ¿hasta qué punto puede hablarse de identidades y comunidades "alternativas» cuando ocurre que estas se constituyen a partir de mercancías transnacionales de una cultura de masas cada vez más popularizada en la era digital? En principio, podría argumentarse que esto es posible porque, a nivel nacional, el otakismo sigue conllevando consumos y prácticas de nicho, sosteniendo su exclusividad y su diferencia respecto de las corrientes mediáticas dominantes y las narrativas totalizadoras a través de esquemas particulares de reputación basados en el compromiso con un tipo de consumo mediático-cultural todavía devaluado o poco convencional (Eng, 2012). Así, fuera de Japón, «los fans del manga y del animé se caracterizan por cierta alternatividad en tanto fans de una cultura de masas extranjera» (Ito 2012, 17-18), consumidores de contenidos diferentes y marginales respecto de lo mainstream en los que encuentran tanto una estética distinta como una narrativa compleja y realista que contrasta con Disney y Hollywood (Napier 2001; Poitras 2001).

Tal dimensión diferencial, a su vez, se relacionaría con las representaciones y los valores distintivos a los que estos fans acceden mediante sus consumos de animé, propios de una cosmovisión oriental que tiende a aparecer exotizada de modo esencialista como alteridad radical en relación con Occidente (Ortiz, 2003). Como afirma Matt Hills (2002), la alternatividad de los otakus occidentales radica en que se vinculan con prácticas de consumo de productos mediáticos japoneses no dominantes en los contextos nacionales en los que viven, en tanto que tratan de mantenerse por fuera del mainstream estadounidense, apropiándose de las expresiones idiomáticas, las representaciones sociales y los valores culturales que ponen en circulación. Para dicho autor, tales apropiaciones son las que permiten explicar el sentido en que estos fans ejercen una solidaridad semiótica con sus pares nipones al reivindicar con orgullo el término "otaku», todavía fuertemente estigmatizado, y utilizarlo como categoría de autoidentificación.

No obstante, cabe remarcar que dicha «alternatividad» paradójica de identidades y comunidades «cosmopolitas» no necesariamente se vinculan con prácticas que den lugar a interpretaciones en clave de «resistencia» respecto del canon de los contenidos que se consumen o de los valores socioculturales hegemónicos, así como tampoco se trata de una condición reivindicada orgullosamente por todos los otakus. A diferencia de lo que suele postularse en la mayoría de los trabajos inscriptos en el campo de los estudios sobre fans (Prego-Nieto 2020), los fans no tienen siempre la necesidad de producir textos «alternativos» a partir de sus consumos, sino que, por el contrario, pueden simplemente apropiarse de estos ellos como fuente de placer y significado. Siguiendo esta línea, podría sostenerse que los otakus encuentran en el animé valores que les permiten procesar sus vidas y relaciones sociales, valiéndose de los diversos recursos que ofrece el fanatismo en general (Borda 2012). Y este pareciera ser el caso de gran parte de los otakus argentinos que suelen racionalizar su fanatismo por objetos de la cultura de masas japonesa a partir de narrativas en las que la nostalgia aparece como un tema central.

En efecto, en el contexto de digitalización actual donde el fanatismo se convierte en parte de la vida cotidiana, se potencia la nostalgia por contenidos antiguos 
asociados a la infancia mediante su remediatización (Geraghty 2018). Dentro de dicho panorama es que se ha llegado a afirmar que asistimos a una suerte de «invasión de las culturas nerd, geek y friki», como se titula un libro de Alejandro Soifer (2012), culturas con las que tiende a presuponerse que el otakismo se vincularía linealmente, dada la creciente visibilización e importancia que cobraron gracias a internet consumos culturales diferenciales y «nostálgicos» como los cómics, películas clase B, juegos de rol, títulos medievales y de fantasía, videojuegos clásicos.

Aquí cabe subrayar un caso de reciente impacto entre los otakus argentinos. Desde 2016, al calor del proyecto online de fans conocido bajo el hashtag \#QueVuelvaMagicKids ${ }^{9}$, mítico canal nacional de televisión por cable, cuyas transmisiones se extendieron entre 1995 y 2006, que constituye un pilar de la historia de este fandom en la Argentina y que es muy recordado con nostalgia por quienes transitaron su infancia durante los noventa dada la amplia cantidad de títulos de animé en su grilla de programación, comenzaron a volver a aparecer con una fuerza en las plataformas digitales figuras asociadas con sus programas emblemáticos, como Gabriela Roife, conductora de A Jugar con Hugo.

Si bien dentro de la comunidad otaku existe el cuestionamiento a los fans de «la vieja escuela», en ocasiones referenciados como "oldfags» o «nostalfags»-que se creerían superiores debido a que por su edad llevan más tiempo en el fandom y sobrevalorarían el pasado sin advertir que los contenidos actuales también pueden ser de buena calidad tanto estética como narrativa-, resulta minoritario. De este modo, termina legitimándose como perspectiva dominante del otakismo la nostalgia por la infancia de lo que podría clasificarse como la generación de los noventa (Álvarez Gandolfi 2017), época asociada con las cintas de VHS, las revistas argentinas con notas sobre productos culturales japoneses, como la Lazer que se publicó entre 1997 y 2009, y una mayor transmisión de animaciones niponas por el medio tradicional televisivo.

A tal punto cobra relevancia identitaria dicha nostalgia que se convierte en un modo de resignificar uno de los estigmas que pesan sobre los otakus: aquél según el cual se trataría de sujetos «inmaduros», fans que no pueden renunciar a consumos que, por su carácter animado, desde el sentido común adultocéntrico tienden a ser asociados linealmente con los públicos infantiles y contenidos edulcorados, simples o inocentes. Ocurre que, según ya se advirtió, la estética y las narrativas de las animaciones japonesas poco tienen de simpleza e inocencia o, al menos, no todos sus títulos son homologables bajo tales características. Motivo por el cual gran parte de los otakus suele realizar afirmaciones tales como las que se citan a continuación a modo de ejemplo, tomadas de entrevistas desarrolladas de nuestros respectivos trabajos de campo según ya se explicitó: «nuestro fanatismo no es una cuestión de inmadurez, es una cuestión de nostalgia que nos permite

9 Este proyecto demuestra que dicho canal sigue presente en la memoria constitutiva del otakismo, interpelando a estos fans con retransmisiones vía Facebook de programas registrados en videos caseros. 
recordar nuestra hermosa infancia»; "somos grandes y por eso nos gusta el animé, por su arte y la complejidad de sus historias y personajes».

Podría inferirse que las identidades fan construidas a partir del otakismo se vinculan fuertemente con la niñez y, en caso de no resignificarlas durante la juventud o la adultez, pasan a ser estigmatizadas como signo de inmadurez o ridiculez, prácticas de consumo no adecuadas para la edad desde una mirada exógena. Si bien en el fandom se entiende que el animé no es solo para chicos, sino que por el contrario se vincula con imágenes y temas tanto fuertes como complejas, su asociación con la niñez es referida por estos sujetos recurrentemente y valorada de modo positivo. Esto se condice con los planteos de Lincoln Geraghty (2018) sobre cómo la nostalgia puede ser comprendida como una actitud desde la cual apropiarse de la disponibilidad de lo residual para la construcción de identidades sociales. Disponibilidad cada vez mayor gracias a la remediatización por la que contenidos mediático-culturales antiguos vuelven a circular de la mano de la digitalización. En función de estas dinámicas, podría pensarse que el animé es reificado como un objeto totémico, ícono de una infancia romantizada como edad de oro.

Al consumir objetos de la cultura de masas japonesa una vez finalizada su niñez, los otakus vuelven a conectarse con emociones que sintieron durante la infancia, apropiándose nostálgicamente de ellos. Ahora bien, esto no quita que la nostalgia también pueda generar fragmentaciones, ilustrando las tensiones endógenas entre los factores aglutinantes de unificación y los factores expulsivos de distinción. Como advierte Matt Hills, en la medida en que para los fans sus objetos de afecto son un componente crucial de sus narrativas identitarias, todas las amenazas externas a dichos objetos totémicos «pueden ser sentidas como amenazas a estas narrativas identitarias» $(2017,114)$.

De aquí que los otakus suelan condenar todo lo que evalúen como un cambio o desviación respecto del canon establecido a partir de la niñez, fundamentalmente aquellos fans vinculados con la generación de los noventa, afirmando que «arruina la infancia», según se retoma a modo de ejemplo otra de las citas que surgieron de las entrevistas respectivas a nuestros trabajos de campo, de acuerdo con lo ya explicado. Y es según este criterio que, asimismo, tienden a juzgar que los fans de la nueva escuela "arruinaron el fandom». De este modo, la agresividad que atraviesa los discursos hostiles que pesan sobre los otakus que se englobarían en la generación de los dos mil, usualmente categorizados como "otacos posers» (Álvarez Gandolfi 2014), se corresponde con lo que, a nivel del fanatismo en general, son «funciones instrumentales dentro del grupo, como el fortalecimiento de sus normas, la construcción de su cohesión y la defensa contra los outsiders» (Zubernis \& Larsen 2012, 121).

Siguiendo esta línea, William Proctor (2017) postula un «proteccionismo fan» por el que también pueden ser atacados los insiders que se considere que amenazan la imagen del objeto totémico y, en consecuencia, la imagen de los fans y del fandom. Según la pertenencia generacional de los otakus, entonces, puede llegar a darse una situación por la cual el advertido incremento del número de fans de los objetos de la cultura de masas japonesa en Argentina no sea celebrado, sino más bien 
repelido para tratar de mantener cierto esoterismo y así sostener el valor diferencial de la alternatividad constitutiva de la identidad otaku, ante la masividad y ampliación del acceso a los contenidos sobre los que se construye. Por eso es que, paradójicamente, desde el discurso de circulación dominante dentro del fandom, se critica a quienes se supone que se creen "únicos y diferentes», categoría mediante la cual también se marca a los fans más jóvenes. Crítica que se sustenta bajo el motivo de que los "otacos posers» los harían quedar en ridículo frente al resto de la sociedad, dando una justificación para ser rechazados por ella. De este modo, se terminan dejando sin cuestionamiento los estigmas dominantes sobre el otakismo, sea invirtiéndolos para reivindicarlos como emblemas identitarios, sea reproduciéndolos en el interior de la comunidad para distinguirse de quienes no serían «verdaderos otakus».

Dentro de cada universo simbólico y organización comunitaria alrededor de los que se estructuran las culturas fan existen jerarquías y estatus (Hills 2002). En función de ellos es que podría pensarse que hay representaciones, prácticas, objetos, sujetos y significados con mayor legitimidad que otros: los otakus de la «vieja escuela» tienden a colocarse simbólicamente por encima del resto y a cuestionar los consumos y las actitudes de los "otacos posers». La condición de «experto/especialista» que otorgaría la posesión de una mayor cantidad de saberes se vincula estrechamente con la mayor cantidad de tiempo que se experimentó el consumo de objetos de la cultura de masas japonesa. En este sentido, puede pensarse que la distinción intracomunitaria entre «los otakus verdaderos de la vieja escuela» y «los otacos posers de la nueva escuela» también se sostiene sobre la base de un acceso directo a las primeras experiencias de consumo de tales bienes nipones en la Argentina: a través de canales de televisión como Magic Kids, videocasetes y revistas temáticas impresas -como las ediciones de Lazer-que tanto valoran los primeros.

Esas experiencias darían autenticidad al otakismo, por lo que «los posers» suelen ser calificados como aquellos que consumen lo que está de moda a través de internet, no siendo capaces de establecer una distancia crítica ni de poner en juego un criterio estético, y por tanto carecerían de la erudición y las vivencias de primera mano que se consideran necesarias para ser un "verdadero otaku», de modo que solo buscarían sentirse aceptados y pertenecer a un colectivo, más allá del referente identitario en cuestión. A su vez, la prefigurada ignorancia de «los posers» se asocia con su caracterización despectiva como «weebs» (de wanna be Japanese), adjudicada tanto al menor tiempo que llevan dentro del fandom otaku como a su condición de "creerse japoneses» por el hecho de repetir constantemente solo algunas palabras -o expresiones onomatopéyicas o gráficasde uso frecuente en los contenidos nipones. Tal como se sugirió en un trabajo previo (Álvarez Gandolfi 2017), así se reproducen los estigmas propios de las representaciones dominantes de los fans como "obsesionados», «excesivos» o «ridículos»: estos estigmas parecieran no ser rechazados, sino más bien redirigidos hacia los «otacos» más jóvenes, «inmaduros» que «no saben ubicarse», quienes tienden a ser responsabilizados por los prejuicios que pesan sobre el fandom otaku. 
Todas estas observaciones permiten afirmar que, en el otakismo, la nostalgia no solo se pone a jugar como un criterio de autoafirmación de las identidades personales y colectivas, sino también como un criterio de distinción intracomunitaria.

\section{Cierres parciales}

A lo largo de estas páginas, hemos planteado reflexiones alrededor de las identidades que pueden construirse a partir del consumo de productos transnacionales como el animé con un doble propósito: por un lado, para revisar modos posibles de conceptualizar el fanatismo en nuestras sociedades contemporáneas, globalizadas y digitalizadas; por otro lado, para repensar las maneras celebratorias en las que muchas veces suelen ser concebidas las prácticas de prosumo otaku en un aparente contexto posmoderno considerado a priori como generador de un mundo sin fronteras ni jerarquías.

Recientemente ha empezado a plantearse que el otakismo se ha «normalizado», de modo que hay quienes afirman tajantemente que las construcciones identitarias y la configuración comunitaria que tienen lugar a partir de este fenómeno ya no cargarían con los estigmas de antaño. Quizás así se explicaría la identificación de referencias mediatizadas cada vez más comunes entre figuras públicas, por ejemplo, ligadas al ámbito del fútbol, de la música o de la televisión argentina: desde la declaración de Ezequiel «Dibu» Martínez, arquero de la Selección Argentina de fútbol masculino recientemente campeona de la Copa América 2021, con la que elegimos titular este artículo para ilustrar la mayor visibilidad de las mezclas entre referentes nacionales y referentes japoneses, como aquellos vinculados con Vegeta y la transformación en Súper Saiyajin que remiten a Dragon Ball Z, o el tatuaje de Goku que el jugador de la Selección Brasileña de fútbol masculino Neymar tiene en su espalda; pasando por la reversión del opening o canción introductoria de animé que hace de «El poder nuestro es» la banda de cumbia villera Supermerk2, y tanto por los pelos teñidos de colores como por los gestos karatekas que frecuentaba el fallecido cantante cordobés de cuarteto Rodrigo Bueno; hasta llegar a la indignación del conductor Iván de Pineda en el programa Pasapalabra porque unos participantes le confesaron que nunca habían visto Naruto.

Sin embargo, no debemos confundir mayor visibilidad con mayor aceptación, al mismo tiempo que tampoco debemos confundir consumo con adscripción identitaria y sentimiento de pertenencia comunitaria. Si bien el consumo de bienes culturas japoneses es una de las puertas de entrada al fandom otaku argentino, no es posible adjudicar linealmente toda remisión a este universo simbólico al hecho de «ser otaku».

Por otro lado, advertimos que, si bien sigue siendo necesario problematizar los sentidos sociomediáticos dominantes desde los que todavía se estigmatiza a los otakus como fans meramente "consumistas», «irreflexivos» y "acríticos», "raros» e «inmaduros», tal problematización no puede olvidar la reconstrucción y el correspondiente cuestionamiento de las asimetrías y desigualdades que atraviesan 
su propio fandom, que puede concebirse como un caso para volver a pensar las persistentes jerarquías culturales escamoteadas mediante conceptos como «hibridación» (Alabarces 2021).

Estamos de acuerdo en que el otakismo implica un fenómeno transnacional, transgeneracional y transclasista. Pero no por ello da lugar a una comunidad armónica de pares que tienen intereses y gustos en común, por lo que destacamos la necesidad de entender al consumo como un campo de batalla por el sentido y de aprehender la complejidad de los entrecruzamientos, de carácter irreductiblemente paradójico. De este modo, puede comprenderse que este fanatismo sea a la vez global y nacional, signado por la alternatividad y la reproducción de lo dominante, racionalizado a partir de la idealización de la infancia como edad de oro y de «lo japonés» como fascinante por su estética y sus narrativas, por sus mezclas entre lo tradicional y lo (pos)moderno.

Ante la caída de los grandes relatos y la hiperfragmentación de la experiencia social, el fanatismo por objetos de la cultura de masas japonesa puede ser analizado como un recurso de construcción y sostenimiento de identidades personales en referentes colectivos. Sin embargo, la customización de la experiencia social sigue condicionada por la determinación de las disposiciones de las industrias japonesas del entretenimiento, así como por conflictos intergeneracionales entre «la vieja escuela» y los "otacos posers». Estos sujetos comparten códigos comunes, pero diversamente valorados. Conscientes de su persistente ilegitimidad, estos fans tratan de legitimarse distinguiéndose internamente.

$Y$, como se viene advirtiendo desde hace ya algunos años, en el otakismo la pertenencia etario-generacional se articula como clivaje de jerarquización y factor expulsivo con la pertenencia de clase (Álvarez Gandolfi 2014; 2016; 2017). Por lo tanto, resulta interesante formular nuevos interrogantes que profundicen sobre dicha articulación, que podrían tomar de ejemplo los casos del cosplay y del waifuismo (Del Vigo \& Carpenzano 2014; Del Vigo 2018), u obras audiovisuales como los AMV que yuxtaponen escenas de animé con canciones de cumbia villera, para relevar cómo allí se ponen en juego mecanismos de segregación. Estas cuestiones quedan abiertas para seguir discutiendo a futuro.

\section{Bibliografía}

AlabARCES, Pablo. 2021. Pospopulares: Las culturas populares después de la hibridación. Bielefeld: BIUP.

Álvarez GandolfI, Federico. 2014. Subcultura otaku. Tesis de Licenciatura en Ciencias de la Comunicación. Buenos Aires: Facultad de Ciencias Sociales, UBA.

Álvarez GANDOLFI, Federico. 2016. «La cultura otaku y el consumo fan de manga-animé en Argentina: entre el posmodernismo y la convergencia». En Vozes \& Diálogo 15 (1), 24-36. <https://tinyurl.com/c8dtp3tj>.

ÁlvareZ GANDOLFI, Federico. 2017. Fanatismos contemporáneos y cultura de la convergencia. Un estudio online sobre la construcción de identidades juveniles en torno del consumo de manga y animé en Argentina. Tesis de Maestría en Comunicación y Cultura. Buenos Aires: Facultad de Ciencias Sociales, UBA.

AzUMA, Hiroki. 2012. "Database animals». En Fandom Unbound. Otaku 
Culture in a Connected World, ed. Ito, Mizuko, Daisuke Okabe \& Izumi Tsuji, New Haven: Yale University Press.

BAUMAN, Zygmunt. 2003. Modernidad líquida. Ciudad de México: FCE.

BerardI, Franco. 2017. Fenomenología del fin. Buenos Aires: Caja Negra.

BORDA, Libertad. 2012. Bettymaníacos, luzmarianas y mompirris. El fanatismo en los foros de telenovelas. Tesis de Doctorado en Ciencias Sociales. Buenos Aires, Argentina: UBA.

BORDA, Libertad \& Federico Álvarez Gandolfi. 2014. «El silencio de los otakus. Estereotipos mediáticos y contra-estrategias de representación». En Papeles de Trabajo, 8 (14), 50-76. <https://tinyurl.com/v7wtuwny>.

COPPA, Francesca. 2014. "Fuck Yeah, Fandom is Beautiful». En Journal of Fandom Studies, 2 (1), 73-82.

DE CerTEAU, Michel. 1996. La invención de lo cotidiano. I. Artes de hacer. Ciudad de México: Universidad Iberoamericana.

DEL VIGO, Gerardo Ariel. 2018. «Love of my Wife. Waifuismo, hiperrealidad y fanatismo 360». En Unidad Sociológica, 3 (11), 100-107. $<$ https://tinyurl.com/2nnw6a2d $>$.

DeL VIGO, Gerardo \& Noelia Carpenzano. 2014. Más allá del mundo feliz del fin de semana: cosplay en la Argentina. Tesina de Licenciatura en Ciencias de la Comunicación. Buenos Aires: Facultad de Ciencias Sociales, UBA.

ENG, Lawrence. 2012. "Strategies of Engagement. Discovering, Defining, and Describing Otaku Culture in the United States». En Fandom Unbound. Otaku Culture in a Connected World, ed. Ito, Mizuko, Daisuke Okabe \& Izumi Tsuji, New Haven: Yale University Press.

GaRCía CANCLINI, Néstor. 1995. «Culturas populares, culturas híbridas, culturas del consumo». En Causas y Azares, 2.

GARCíA NúNEZ, Roberto \& Dassaev García Huerta. 2014. «Una aproximación a los estudios sobre los otakus en Latinoamérica». En Contextualizaciones Latinoamericanas, 6 (10), 1-9.

GeraghtY, Lincoln. 2014. Cult Collectors. Nostalgia, Fandom and Collecting Popular Culture. Londres: Routledge.

GERAGHTY, Lincoln. 2018. "Nostalgia, fandom and the remediation of children's culture». En A Companion to Media Fandom and Fan Studies, ed. Booth, Paul, Nueva York: Wiley-Blackwell.

HILLS, Matt. 2017. «From Fan Culture/Community to the Fan World: Possible Pathways and Ways of Having Done Fandom». En Palabra Clave, 20 (4), 856-883.

HILLS, Matt. 2002. Fan Cultures. Nueva York: Routledge.

ITO, Mizuko. 2012. "Introduction». En Fandom Unbound. Otaku Culture in a Connected World, ed. Ito, Mizuko, Daisuke Okabe \& Izumi Tsuji, New Haven: Yale University Press.

JenkINS, Henry, Danah Boyd \& Mizuko Ito. 2016. Participatory Culture in a Networked Era. Cambridge: Polity Press.

LYOTARD, Jean-François. 1987. La condición postmoderna. Madrid: Cátedra.

MARTín-BARBERO, Jesús. 2008. «Estallido de los relatos y pluralización de las lecturas». En Comunicar, 15 (30), 15-20.

MARTín-BARBERO, Jesús. 1995. Secularización, desencantamiento y reencantamiento del mundo. Ciudad de México: FCE.

NAPIER, Susan. 2001. Anime From Akira to Princess Mononoke. Experiencing Contemporary Japanese Animation. Nueva York: Palgrave Macmillan.

ORTIZ, Renato. 2003. Lo próximo y lo distante. Japón y la modernidad-mundo. Buenos Aires: Interzona.

ORTIZ, Renato. 1997. Mundialización y cultura. Bogotá: CAB.

Poltras, Gilles. 2001. Anime Essentials: Every Thing A Fan Needs To Know. Berkeley, C.A.: Stone Bridge Press.

PreCIADO, Paul B. 2008. Testo Yonqui. Madrid: Espasa. 
Prego-Nieto, Marta. 2020. «Tendencias epistemológicas de los 'fan studies' en la investigación en comunicación: una propuesta de clasificación». En Anàlisi: quaderns de comunicación i cultura, (63), 1-14.

Proctor, William. 2017. «Bitches Ain't Gonna Hunt No Ghosts: Totemic Nostalgia, Toxic Fandom and the Ghostbusters Platonic». En Palabra Clave, 20 (4), 105-114.

SARLO, Beatriz. 1994. Escenas de la vida posmoderna. Buenos Aires: Siglo XXI.

SOIFER, Alejandro. 2012. Que la fuerza te acompañe. La invasión de las culturas nerd, geek y friki. Buenos Aires: Marea.

SUNKEL, Guillermo. 2002. Una mirada otra. La cultura desde el consumo. Buenos Aires: CLACSO.

ZUBERNIS, Lynn \& Katherine Larsen. 2012. "Taking sides: Business or Pleasure?». En Fandom At The Crossroads. Celebration, Shame and Fan/Producer Relationships. Newcastle: Cambridge Scholars Publishing.

\section{Resumen}

En el presente artículo nos proponemos reflexionar sobre los procesos de construcción identitaria que se despliegan en torno del fanatismo en la Argentina por objetos de la cultura de masas japonesa, conceptualizado en términos de otakismo (Álvarez Gandolfi 2016). Para ello, analizaremos cómo los fans de contenidos como el animé, (auto)identificados como "otakus», dan sentido a las experiencias vinculadas con sus prácticas de consumo, advirtiendo las tensiones en la constitución de las identidades nacionales de estos sujetos atravesadas por contenidos transnacionales, entre significaciones que adjudican a «lo argentino» y a «lo japonés». Ello en un contexto actual de creciente acceso y circulación global de producciones transculturales, de la mano de la digitalización y la consolidación de la cultura participativa en una era interconectada (Jenkins et al. 2016), dentro del cual nos basaremos en investigaciones empíricas propias (Álvarez Gandolfi 2014; Del Vigo y Carpenzano 2014) consistentes en la aplicación de técnicas cualitativas de entrevista con estos fans y en un relevamiento etnográfico de las principales plataformas digitales en las que interactúan. Por un lado, se plantea que las mencionadas tensiones serían resueltas mediante los prosumos otaku que implican una socialización sexoafectiva y un bricolaje identitario sincrético tanto dislocado como potencialmente resistente en el marco del waifuismo (Del Vigo 2018). Por otro lado, se argumenta que para comprender dichas tensiones que atraviesan los procesos de construcción de identidades a partir del otakismo no pueden olvidarse las dinámicas de fragmentación en el interior del fandom ni las maneras asimétricas en que los fans en cuestión las significan en sus narrativas biográficas nostálgicas. Aquí contrastaremos tales planteos y argumentaciones de modo dialógico, desplegando un recorrido conceptual deudor de los estudios culturales y los estudios sobre fans, y de corrientes como el posmodernismo y sus problematizaciones, en pos de consolidar bases posibles para seguir estudiando este fenómeno cada vez más visible e importante en las sociedades contemporáneas. 


\begin{abstract}
In this article we intend to reflect on the processes of identity construction that unfold around Argentinian fandom of Japanese mass culture, conceptualized in terms of otakism (Álvarez Gandolfi 2016). To do this, we will analyse how fans of content such as anime, (self)identified as "otaku», give meaning to the experiences linked to their consumption practices, noticing the tensions in the constitution of the national identities of these subjects crossed by transnational objects, between meanings that they assign to "the Argentine» and "the Japanese». All of this in a current context of growing access and global circulation of cross-cultural productions, hand in hand with digitization and the consolidation of participatory culture in an interconnected era (Jenkins et al. 2016), within which we will base ourselves on our own empirical research (Álvarez Gandolfi 2014; Del Vigo \& Carpenzano 2014) consisting of the application of qualitative interview techniques with these fans and an ethnographic fieldwork on the main digital platforms through which they interact. On the one hand, we argue that the aforementioned tensions would be resolved through otaku prosums that imply a sex-affective socialization and a syncretic identity bricolage both dislocated and potentially resistant within the framework of waifuism (Del Vigo 2018). On the other hand, we argue that in order to understand the tensions that go through the processes of identity construction based on otakism, the dynamics of fragmentation within the fandom nor the asymmetric ways in which the fans in question signify their favourite contents in their nostalgic biographic narratives cannot be forgotten. Here we will contrast such proposals and arguments in a dialogical way, displaying a conceptual journey that is indebted to cultural studies and fans studies, and currents such as postmodernism and its problematizations, in order to consolidate possible bases to continue studying this increasingly visible and important phenomenon in our contemporary societies.
\end{abstract}

